\title{
SEISMIC RISK ANALYSIS OF URBAN NON-ENGINEERED BUILDINGS: APPLICATION TO AN INFORMAL SETTLEMENT IN MÉRIDA, VENEZUELA
}

\author{
A. CASTILLO \\ Faculty of Architecture, Building Technology Department, University of the Andes \\ Complejo La Hechicera, Edif. Arquitectura, Mérida 5101, Venezuela \\ F. LÓPEZ-ALMANSA (corresponding author) \\ Architecture Structures Department, Technical University of Catalonia \\ Avda. Diagonal 649, 08028 Barcelona, Spain \\ L.G. PUJADES \\ Department of Geotechnical Engineering and Geosciences, Technical University of Catalonia \\ C. Jordi Girona 1-3 (D2 Building), 08034 Barcelona, Spain
}

\begin{abstract}
Seismic risk scenarios are obtained for an informal settlement in Mérida (Venezuela), which is representative of an important number of urban areas in earthquake-prone regions of the developing world. The vulnerability indices of the buildings range between 0.64 and 0.80 on a scale of 0 to 1 . In an intensity IX earthquake scenario, more than $32 \%$ of the buildings would suffer damage of grade 4 (extensive) or greater. A structural analysis of the buildings in the study area shows that they are unsafe for gravity loads, and that the seismic demands exceed the strength of the constructions. Simple and comparatively inexpensive measures can improve the seismic performance of these buildings; the vulnerability can be reduced by about $51 \%$. In an intensity IX earthquake scenario the expected economic loss before retrofitting the buildings is US\$5.36 million, with 275 fatalities; once retrofit has been carried out, the resulting figures are US\$0.39 million and 10 fatalities. Retrofit would cost US\$1.04 million, whereas reconstruction would cost US\$19 million.
\end{abstract}

Keywords: Vulnerability, risk, mitigation, non-engineered buildings, seismic strengthening, Venezuela.

\section{Introduction}

During the $20^{\text {th }}$ century, migration from rural to urban areas led to the development of large cities with poor areas characterized by low quality constructions. Consequently, densely populated informal settlements are now increasingly common in most large cities in South America and other developing regions, including China, India and other Asian and African countries. Housing in these areas is generally non-engineered and selfconstructed. Since the buildings are of poor quality and they were not designed in accordance with code provisions on earthquake resistant design, they are expected to show high seismic vulnerability. In addition, settlements of this type frequently occupy high seismic hazard areas and are therefore vulnerable to earthquake-induced effects such as landslides and liquefaction. This combination of hazard and vulnerability generates a significant seismic risk (ISDR, 2001).

Excluding extremely precarious housings and according to their lateral load resisting system, non-engineered dwellings can be broadly classified into seven groups (Murty et al., 2006; EERI/IAEE, 2005; Bolívar, 1994). The following types of buildings can be considered. 1) adobe or earth houses, with timber or similar roofs and slabs; 2) stone masonry, which includes buildings with rubble, field and simple stone walls with wooden floors; 3) timber houses, which can incorporate either frames or posts and ties; 4) unconfined unreinforced masonry walls; 5) confined unreinforced masonry walls, in 
which the confinement effect is provided by RC posts cast after the walls have been erected; 6) $R C$ frames, which are usually supplemented with infill walls, although in any case the main frames are able to resist the vertical loads; and 7) intermediate $R C$ frames and confined masonry walls, which consist of a light RC frame which is then filled with unreinforced masonry walls. Importantly, the latter group cannot be considered simply as $R C$ frames, since the strength of the frame is not sufficient to withstand the gravity loads, or as confined masonry walls, because the columns, which are cast before the walls are constructed, do not provide enough confinement and the bottom walls have no foundation. Of these construction techniques, adobe, stone masonry and timber (groups 1 to 3) are more commonly used in rural areas because these materials are more readily available. In contrast, masonry and concrete-based construction (groups 4 to 7) are used, widely and increasingly, in urban areas. Usually, all of these buildings are characterized by low ductility and by high lateral stiffness, thus leading to high seismic forces; they are furthermore vulnerable to earthquakes because they are non-engineered and because of the low quality of the materials.

The main goals of this research are to analyze the seismic risk of informal urban settlements and to propose simple and feasible -but effective- seismic retrofit measures to protect buildings in these areas against earthquakes. The city of Mérida in Venezuela was chosen as a test site. The "La Milagrosa" area is a typical informal settlement of the city with a wide variety of ground and building conditions. In this settlement, the terrain combines steep and flat areas and soft and hard soils. Buildings are mainly intermediate $R C$ frames and confined masonry walls (group 7). The area is suitable for the aims of this study because it is representative of the suburbs of an important number of large conurbations in developing countries in seismic-prone regions. The study of "La Milagrosa" consists of the following steps: (1) classification of the building stock; (2) vulnerability and risk analysis, (3) structural analysis and proposal of seismic strengthening measures, and (4) socio-economic cost-benefit appraisal.

\section{Mérida and "La Milagrosa"}

\subsection{Mérida city}

Mérida is located in the Andean mountain range in Venezuela and it was founded in 1558 on a plateau between the Albarregas and Chama rivers, which divide the city into two areas separated by a shallow and a deep canyon. The Chama river canyon confines the urban area on one side of the city, at the base of the Sierra Nevada mountain chain. Altitudes in the tableland range from around $1100 \mathrm{~m}$ in the southeastern part to $1900 \mathrm{~m}$ at the northwestern limits. Mérida has grown steadily since it was founded and now has more than 280,000 inhabitants. In the last four decades, a number of informal settlements have grown around the city limits and are now home to approximately one third of the city's population. These settlements are the most densely populated areas of the city and have the highest vulnerability and even the greatest seismic hazard in some steep sites. 


\section{2. “La Milagrosa” settlement}

"La Milagrosa" is a suburb located in the northeastern part of the city. Figure 1 shows the elevation range in Mérida, the main rivers and streets and the location of the settlement. The relief in this area is extremely varied, with gradients ranging from near flat ( 0 to $5 \%$ ) to steep $(60 \%)$. Clay rock outcrops predominate in the steeper and upper parts, and there are average to good quality soils in the rest of the area. The design stress is estimated as $0.15 \mathrm{MPa}$, since no tests have been carried out locally and there is no information about geotechnical columns. With the exception of landslide risk, the soil strength is not critical; since the buildings are light and have a small number of floors, the vertical stresses they exert are comparatively low.

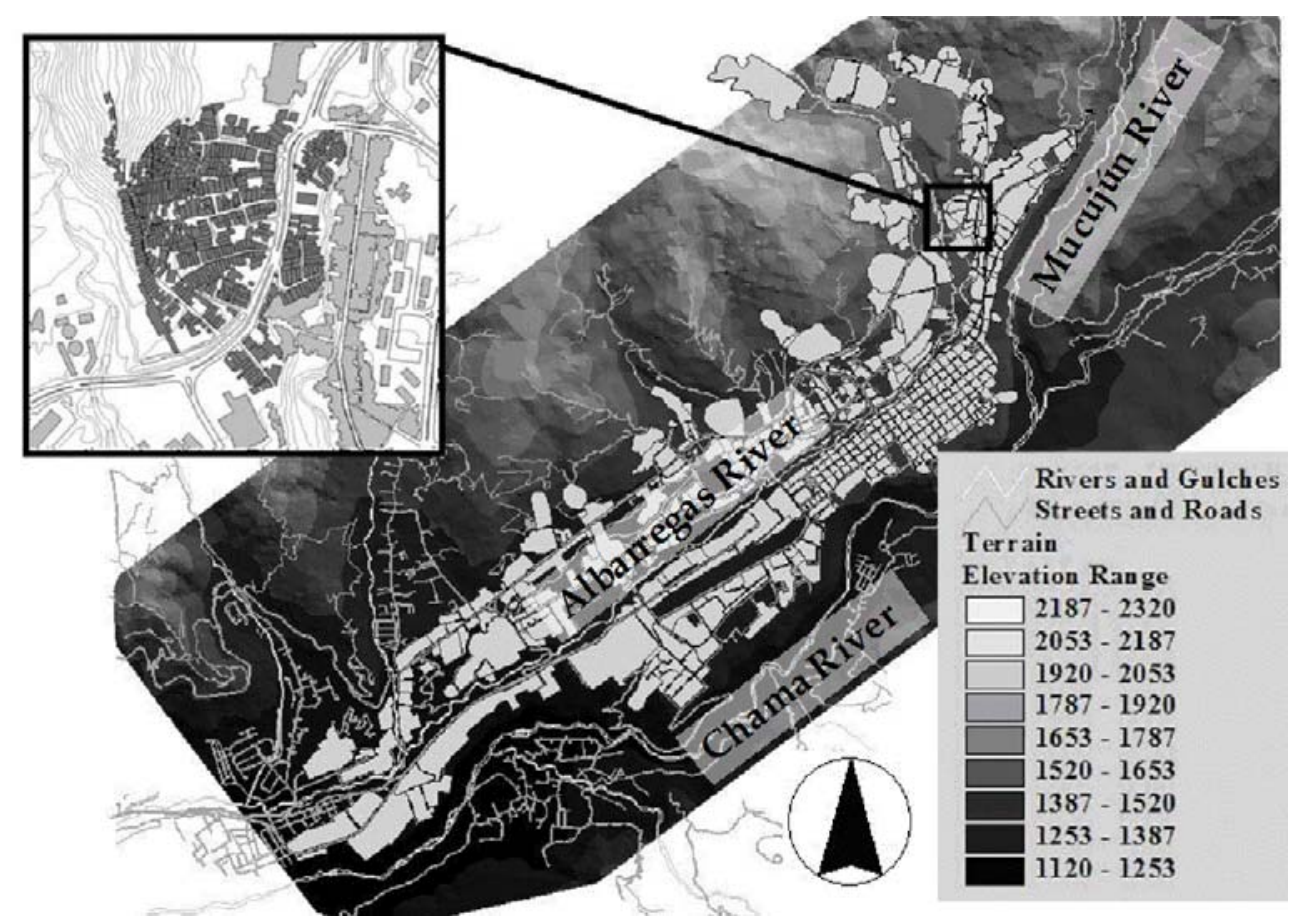

Fig. 1. Elevation range, rivers and streets of the Mérida plateau.

This suburb was chosen because its buildings are representative of those found in an important number of informal settlements in developing countries. The area is divided into four sectors: "La Milagrosa", "Cristo Rey", "Los Molinos" and "Miranda". Figure 2 shows a map of the suburb and Table 1 lists the main features of each sector. The "La Milagrosa" settlement contains mainly houses, which can be classified into groups according to their resisting systems, as shown in Table 2. 


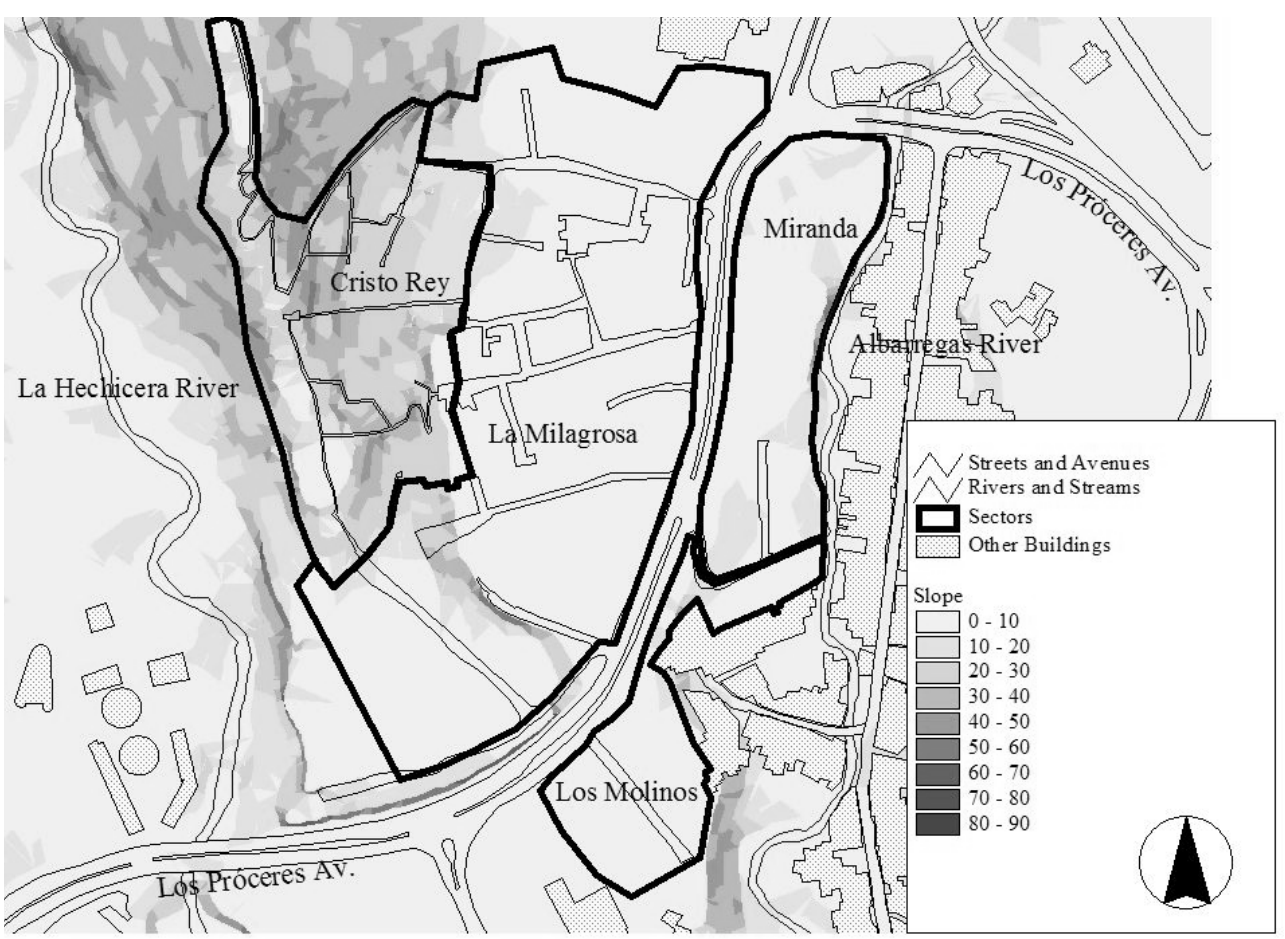

Fig. 2. Sectors in the "La Milagrosa" settlement.

The last two categories in Table 2 correspond to engineered constructions. The data show that $95 \%$ of the buildings are non-engineered intermediate $R C$ frames and confined masonry walls (group 7), so the paper focuses mainly on this structural type.

Table 1. Description of sectors in the "La Milagrosa" area

\begin{tabular}{|c|c|c|c|c|}
\hline Sector & Surface (Ha) & $\mathrm{N}^{\mathrm{o}}$ of buildings & $\mathrm{N}^{\mathrm{o}}$ of inhabitants & Year of foundation \\
\hline La Milagrosa & 5.68 & 219 & 1608 & 1960 \\
\hline Cristo Rey & 2.83 & 199 & 1232 & 1962 \\
\hline Los Molinos & 0.82 & 37 & 280 & 1962 \\
\hline Miranda & 1.31 & 78 & 620 & 1965 \\
\hline Total & 10.64 & 533 & 3740 & \\
\hline
\end{tabular}

Approximately $85 \%$ of the buildings have a rectangular plan configuration, with typical plan dimensions of $5.5 \times 16.5 \mathrm{~m}$. The main occupancy is housing, and in the most common scenario a family of five (parents and three children) occupies each floor. Additional floors are constructed to house new families, resulting in a typical vertical 
growth pattern, although the buildings rarely exceed three floors. This pattern is common to an important number of informal urban settlements worldwide

Table 2. Distribution of building types in "La Milagrosa”

\begin{tabular}{ccc}
\hline Building type & $\mathrm{N}^{\mathrm{o}}$ of buildings & Percentage of total \\
\hline Intermediate RC frames and confined masonry walls & 506 & 94.93 \\
Unconfined unreinforced masonry walls & 10 & 1.88 \\
RC frames & 2 & 0.38 \\
Steel frames & 9 & 1.69 \\
RC columns and steel truss beams & 6 & 1.13 \\
\hline Total & 533 & 100
\end{tabular}

Figure 3 shows a map with the plan configuration and the number of floors of the buildings in the "La Milagrosa" settlement

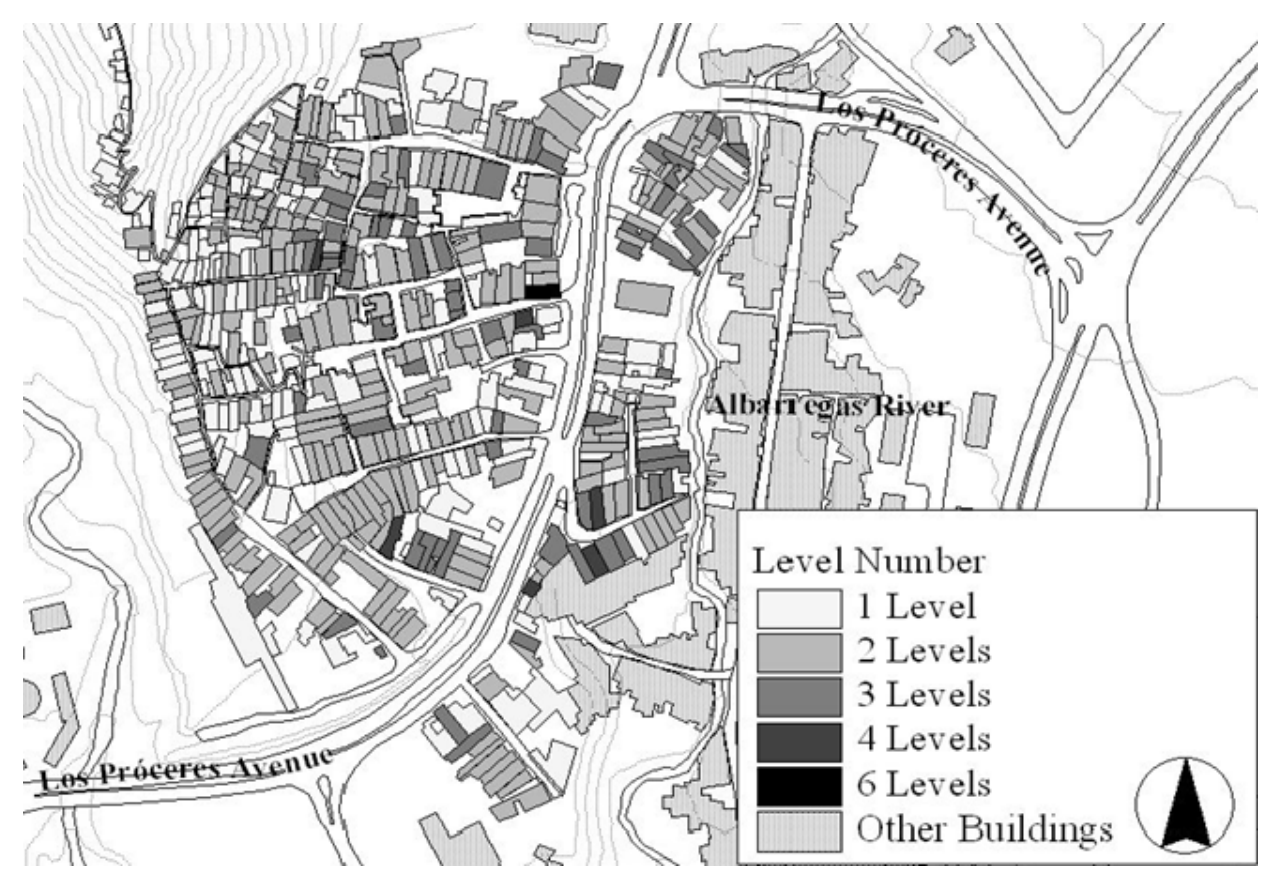

Fig. 3. Plan configuration and number of floors of buildings in the "La Milagrosa" settlement. 


\subsection{Buildings in "La Milagrosa"}

Figure 4 shows sketches of the construction type (left) and of typical reinforcement details (right). The main structural features of the buildings are described below. Detailed comprehensive descriptions can be found in (Castillo, 2006).
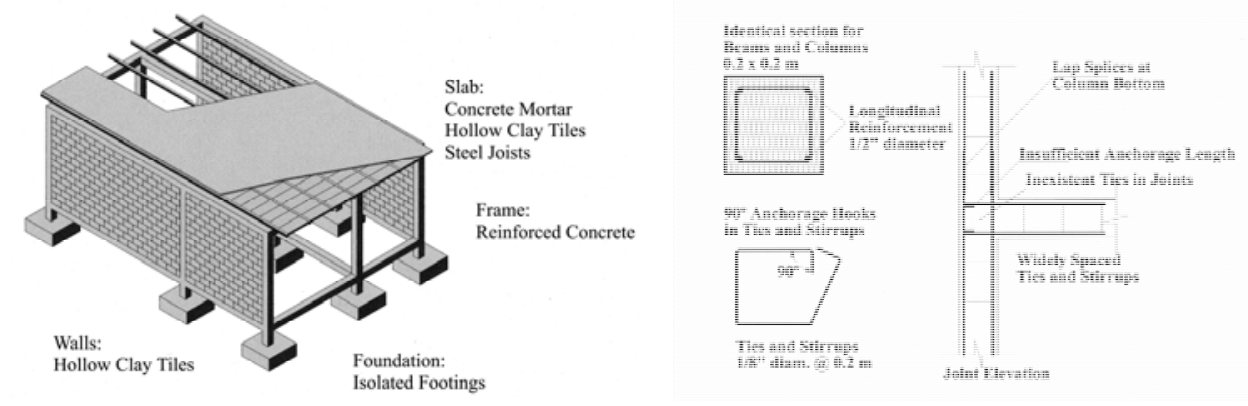

Fig. 4. Structural characteristics of the houses in the "La Milagrosa" settlement.

Posts and ties constitute a light $3 \mathrm{D} \mathrm{RC}$ frame, with an average square section in the beams (ties) and columns (posts) of $20 \mathrm{~cm} \times 20 \mathrm{~cm}$. The main characteristics of the steel reinforcement are described in Figure 4 (right). The bars are deformed (improved adherence) and the steel yielding point is $140 \mathrm{MPa}$. Figure 4 (right) shows that the beamcolumn connections do not have special detailing or stirrups; however, the longitudinal reinforcement bars of the beams have hooked ends. The compressive strength of the concrete was measured with a Schmidt hammer, and the characteristic value is approximately $10 \mathrm{MPa}$. In some cases the joined members are poorly aligned and connected. The supporting walls are built after the posts in running (stretcher) bond, without reinforcement and using low-quality cementitious mortar. The bricks are hollow and not intended for structural use. The characteristic shear and compressive strengths are conservatively estimated as $0.08 \mathrm{MPa}$ and $0.35 \mathrm{MPa}$, respectively (IAEE, 2001). The friction coefficient is taken as 0.4 (ENV-1996, 1996). The walls are usually erected without foundation. The posts are supported by isolated RC footings. The cladding walls run around the entire perimeter, with openings in the front and rear sides only; on the first floor, there is usually one window and one door at the front and two windows at the rear. On the upper levels, there are either two windows or one door and one window (if there is a balcony) at the front and the rear. Not all of the partition walls are aligned with the frame, and in some cases they are not vertically aligned. The walls beneath slabs are referred to as "topped" because the beams produce a certain degree of confinement; those under light roofs are referred to as "un-topped" because the roof is weak and untied and, therefore, does not produce any confinement. The roofing is light and consists mainly of zinc sheathing over steel beams. The roofs are not well fixed to the support elements. The slabs are built using conventional I-shaped steel beams $(80 \mathrm{~mm}$ deep), which are arranged parallel to the longitudinal axis of the building and supported by the transverse RC ties. The inter-axial spacing is filled with hollow clay blocks. The slabs are topped with a thin compressive concrete layer reinforced with a light welded mesh. The first level usually has a front cantilever of between 700 and $900 \mathrm{~mm}$, which supports either masonry cladding walls or balconies. The stairs are constructed either inside or outside the building and are made of steel or reinforced concrete. Although the general quality of the 
constructions is poor, it is better than expected given the adverse conditions. Some common deficiencies include broken masonry units and discontinuities in the walls, bonding mortar that is not even resistant to scratching, unaligned horizontal blocks, roofs that are not properly tied, shrinkage cracks in floors, irregularities, cavities and erosion in the posts and ties, and insufficient reinforcement cover. In some steep sites, soil erosion is observed around the foundations. Finally, no relevant pathologies are observed. Minor problems include humidity, water filtration, and cracks in the wall plaster. Figure 5 shows some representative pictures of the houses in the "La Milagrosa" settlement.
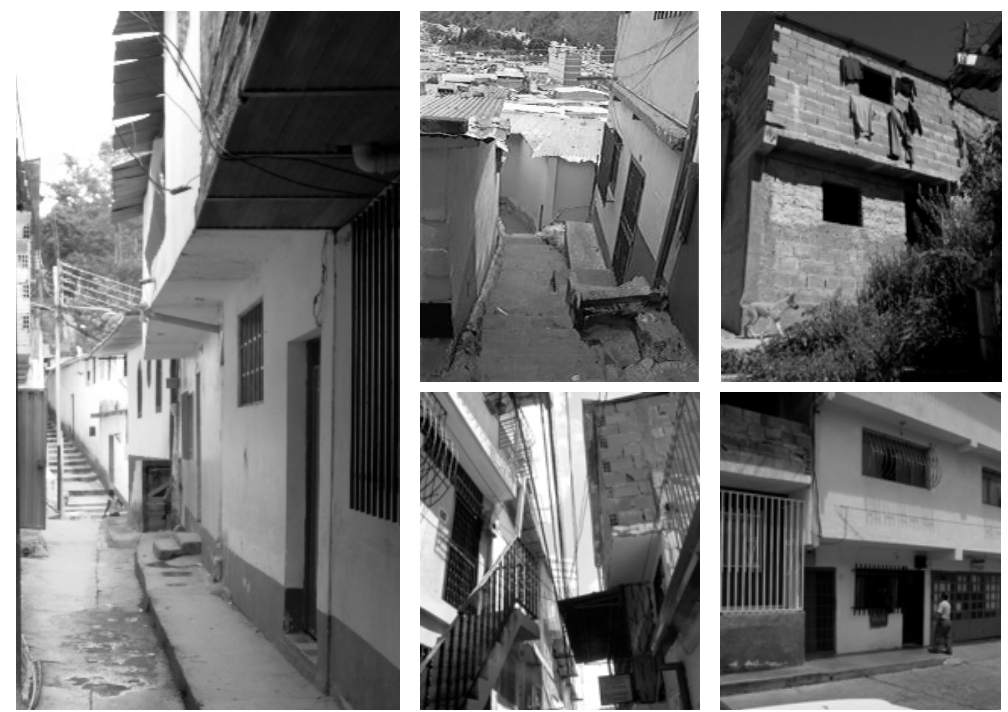

Fig. 5. Buildings in the "La Milagrosa" settlement.

Four prototype buildings were selected to represent the vast majority of houses in "La Milagrosa". The configurations of these buildings are shown in Figure 6. This Figure shows that building B1 has one floor and it is topped with a slab. Building B2 has two floors and it is topped with a light roof. Buildings B3-b and B3-c have three floors and they are topped with light roofs. Building B3-b has balconies whereas building B3-c has a cantilever. Figure 7 shows the plan configurations of these prototypes. Each floor is $2.80 \mathrm{~m}$ high. Interestingly, the eccentricity between the centers of stiffness and gravity on the second and third floors of building B3-c is moderate, so it does not affect the torsional seismic behavior to a significant degree. 


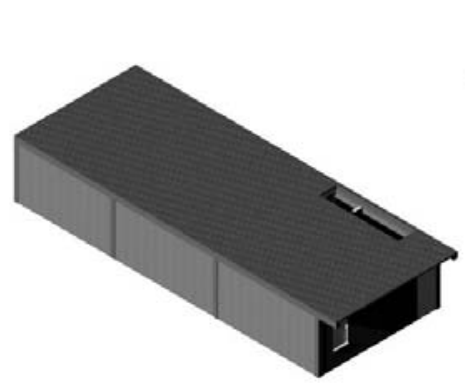

Building B1

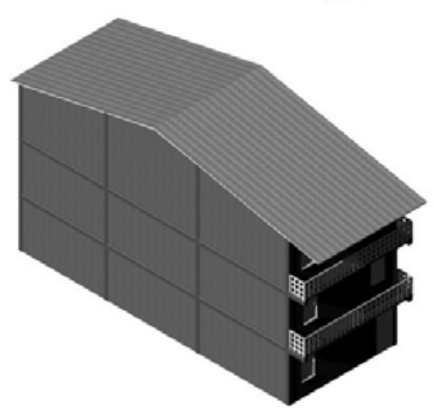

Building B3-b

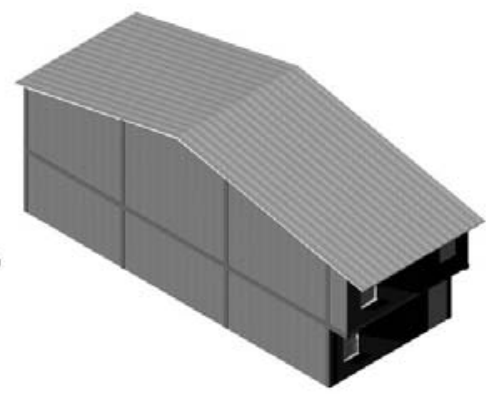

Building B2

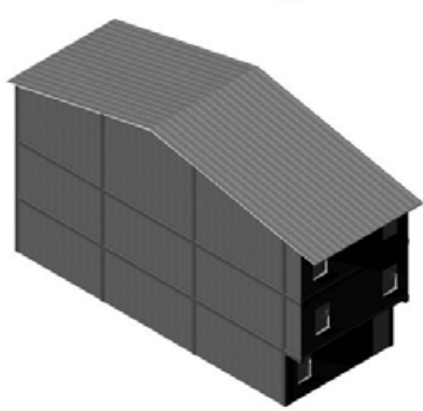

Building B3-c

Fig. 6. Prototype buildings.

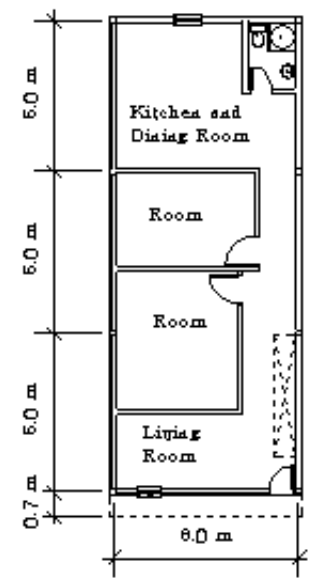

First Floor

Buildings: B1, B2 and B

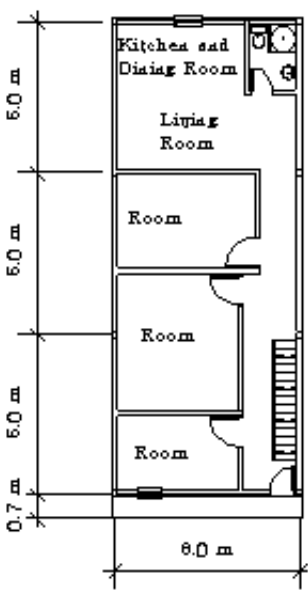

Upper Floors Buildings: $B 2$ and B3-b

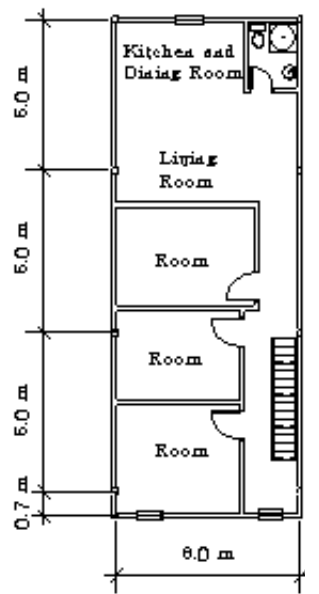

Upp er Floors Buildings: B2 and B3-o

Fig. 7. Plan configurations of the prototype buildings. 


\section{Vulnerability and risk analysis}

\subsection{Vulnerability assessment methods}

Vulnerability assessment is of crucial interest because it allows estimating the seismic resistance of buildings and other constructions. Numerous recent studies are oriented to the development, application and validation of techniques to evaluate the seismic strength of buildings; this knowledge allows predicting the expected damage in populated areas thus enabling better decision making on seismic risk prevention and protection. There are several methods for vulnerability evaluation and numerous applications to urban areas have been reported (ATC-13, 1985; Yépez, 1996; Barbat et al., 1996, 1998, 2006a, 2006b, 2008 and 2009; Lagomarsino and Giovinazzi, 2006; Dolce et al., 2006; Carreño et al., 2007; Park et al., 2009 and Lantada et al., 2009 and 2010). These methods can be broadly classified in two groups: procedures based on vulnerability indices and procedures based on capacity spectra (ATC-40, 1996). In the first group the vulnerability of the building is characterized by an index and the severity of the seismic action is described by its macroseismic intensity; the macroseismic intensity scales consider building typology matrices and/or vulnerability classes (EMS'98) and can be used to calibrate damage functions linking the building vulnerability, the seismic intensity and the expected damage. A thorough review and comparison of the macroseismic scales can be found in Musson et al., (2010). In the methods based on capacity spectra (Lantada et al., 2009; Pujades et al., 2010) the severity of the seismic action is described by response spectra and the vulnerability of the building is represented by capacity and fragility curves. Capacity curves are lateral force vs. top displacement diagrams obtained from nonlinear static analysis (push-over); in their acceleration vs. displacement (AD) format, are termed capacity spectra. From the capacity spectra, simplified techniques can be used to produce fragility curves; such plots represent, for each damage state, its probability of exceedance in terms, for instance, of spectral displacement. Thus, advanced methods for estimating the seismic vulnerability and risk (FEMA/NIBS, 2002; Milutinovic and Trendafiloski, 2003) allow estimating the physical damage expected for a given earthquake scenario as the intersection of the capacity spectrum, which characterizes the vulnerability of the building, with the response spectrum, which quantifies the input severity. That intersection is commonly referred as performance point (or target drift); it corresponds to the spectral displacement produced in the building by the earthquake corresponding to the selected scenario. The probabilities of the different damage states are then obtained from the fragility curves.

An overall comparison among both families of methods shows that those based on vulnerability indices are more suitable for studies on a high number of buildings while the methods based on capacity spectra require a deep knowledge about the structural parameters of the building and, hence, are more adequate for the analysis of single buildings. In the case considered in this paper, the methods based on capacity spectra are particularly inadequate since the structural parameters are deeply unknown and exhibit high scattering. Moreover, the push-over analysis methods are clearly oriented to 
ordinary constructions; its applicability to non-engineered buildings is highly dubious. Simplified methods based on vulnerability indices have been preferred because its application to urban areas is easy and straightforward, leading to good estimates of the expected damage. Previous studies in great cities have shown that the results obtained by using vulnerability indices are in good agreement with the ones obtained by using more sophisticated methods based on capacity spectra (Lantada et al., 2009). The method considered in this work is described in the following subsection.

\subsection{Considered method}

The vulnerability of the buildings in "La Milagrosa" is assessed using the Italian Vulnerability Index Method (IVIM) (Benedetti and Petrini, 1984; Angeletti et al., 1988; Barbat et al., 1996; GNDT, 2001).

As shown in Table 2, most of the buildings (near 95\%) in this settlement belong to the type intermediate RC frames and confined masonry walls. The IVIM method provides evaluation tables for both masonry and reinforced concrete structures. However, the vulnerability parameters for masonry are clearly unsuitable for representing the properties of the considered buildings while those properties are better evaluated by using the IVIM tables for reinforced concrete buildings. Hence, such building type is chosen to represent the constructions in "La Milagrosa".

The vulnerability is defined using an index ranging from 0 (not vulnerable) to 1 (most vulnerable). Such index scores buildings on the basis of eleven parameters that represent their main earthquake-resistant properties; each parameter $i$ is qualified by a coefficient $K_{\mathrm{i}}$, which is weighted by a factor $W_{\mathrm{i}}$. Each $K_{\mathrm{i}}$ coefficient can be assigned one of the following three values: $A$ (no added vulnerability), $B$ (moderate increase in vulnerability) and $C$ (highest contribution to vulnerability). The original method defines eleven parameters, but, since such method was designed for isolated buildings, does not take into account the pounding effect. An additional parameter, called adjacency parameter, is proposed for representing this effect. The description of these parameters is shown in Table 3. It is worth noting that these parameters are useful to evaluate not only reinforced concrete buildings but also our special type of buildings considered as intermediate $R C$ frames and confined masonry walls. In this case it is important to consider the contributions of reinforced concrete frames and confined masonry walls to the evaluation of the parameters. This way, this method facilitates comprehensive assessment of the major deficiencies observed in the buildings in "La Milagrosa". Concerning to the adjacency parameter, it takes into account the following cases: A) the distance to adjacent buildings is sufficient to prevent hammering during strong motions; $B$ ) there are adjacent buildings with the same number of floors whose slabs are at roughly the same level; and $C$ ) there are adjacent buildings with a different number of floors or with slabs that are not at the same level. The original version of IVIM used observed damage data to calibrate the first eleven parameters (GNDT, 2001). Parameter number 12, adjacency, can be calibrated on the basis of expert judgment, observed damage, or numerical modeling (Yépez, 1996). Expert opinion is used here to qualify the adjacency 
parameter. Because the risk of collapse due to pounding is considered serious, it was decided to adopt the maximum score between those provided in the IVIM for the eleven previous parameters. This corresponds to the parameter number 7 (vertical configuration). This way the coefficient $\mathrm{K}_{12}$ is scored as: $0(A), 1(B)$ and $3(C)$. The weighting coefficient was set to $W_{12}=2$, which also corresponds to the weight of parameter number 7 . This choice may seem to overestimate the pounding effect in comparison to other parameters related to the quality of the structure itself. However, it was considered that the quality of the structure is taken into account by a number of parameters, namely parameters $1,2,3,5,8$ and 9 , being well represented in the total vulnerability of the building. Table 3 shows the parameters and the corresponding scores and weights.

The following equation is used to determine the vulnerability index:

$$
I_{V}=\frac{1+\sum_{i=1}^{12} K_{i} W_{i}}{1+\sum_{i=1}^{12} K_{i C} W_{i}}
$$

$K_{\mathrm{i}}$ and $W_{\mathrm{i}}$ are the values, in Table 3 , corresponding to the $i$-parameter and $K_{\mathrm{iC}}$ is the corresponding highest qualification $(C)$. Equation 1 is normalized in such a way that the vulnerability indices $\left(I_{\mathrm{V}}\right)$ range from 0 (no vulnerability) to 1 (highest vulnerability). IVIM also incorporates damage functions which relate expected damage to intensity and vulnerability. However, these functions are calibrated for typical Italian and Spanish buildings. Italian damage functions were obtained from observed damage data, whereas Spanish damage functions also take into account results from numerical simulations (Yépez, 1996). Since there is little or no specific damage data for informal settlements around the world and the configuration of the buildings in these types of areas differs considerably, it is unwise to use such functions in this study.

A new vulnerability-index-based method called New Vulnerability Index Method (NVIM) was developed under an EC-funded research project to provide a specific riskevaluation approach for European cities. The method is based on building types and the vulnerability classes established in the European Macro-seismic Scale EMS'98. A detailed description of the method can be found in (Giovinazzi, 2005; Giovinazzi and Lagomarsino, 2004; Milutinovic and Trendafiloski, 2003; Lantada et al., 2009; Barbat et al., 2006a; Barbat et al., 2006b). NVIM is versatile and easy to implement because it can be applied to any type of building as long as the appropriate vulnerability indices and vulnerability modifying factors are used. In addition, the damage functions are based on macroseismic intensity observations and are therefore fully general. For expected damage, NVIM provides semi-empirical functions which link macroseismic intensity, vulnerability and damage. As stated above, these functions are based on the damage grades and damage descriptions given in EMS'98 (Grünthal, 1998). Six damage grades 
are considered: 0 (no damage), 1 (slight), 2 (moderate), 3 (severe), 4 (extensive) and 5 (complete).

\begin{tabular}{|c|c|c|c|c|c|}
\hline \multirow{2}{*}{ Number } & \multirow{2}{*}{ Parameter } & \multicolumn{3}{|c|}{ Qualification $K_{\mathrm{i}}$} & \multirow{2}{*}{$\begin{array}{c}\text { Weight } \\
W_{\mathrm{i}}\end{array}$} \\
\hline & & $A$ & $B$ & $C$ & \\
\hline 1 & Type and configuration of resisting system & 0 & 1 & 2 & 4 \\
\hline 2 & Quality of resisting system & 0 & 1 & 2 & 1 \\
\hline 3 & Conventional resistance & -1 & 0 & 1 & 1 \\
\hline 4 & Location and soil condition & 0 & 1 & 2 & 1 \\
\hline 5 & Diaphragms & 0 & 1 & 2 & 1 \\
\hline 6 & Plan configuration & 0 & 1 & 2 & 1 \\
\hline 7 & Vertical configuration & 0 & 1 & 3 & 2 \\
\hline 8 & Connectivity between elements & 0 & 1 & 2 & 1 \\
\hline 9 & Low-ductility structural members & 0 & 1 & 2 & 1 \\
\hline 10 & Non-structural elements & 0 & 1 & 2 & 1 \\
\hline 11 & State of preservation & 0 & 1 & 2 & 1 \\
\hline 12 & Adjacency & 0 & 1 & 3 & 2 \\
\hline
\end{tabular}

The expected probability of occurrence of damage grades for any degree of seismic intensity is assumed to follow a binomial distribution (Grünthal, 1998). The probabilities of each damage grade can be calculated using the following equation:

$$
P_{k}(N, d)=\frac{(N-1) !}{(N-1-k) ! k !} d^{k}(1-d)^{N-1-k} \quad k=0 \cdots(N-1)
$$

$N$ is the number of damage grades (here $N=6$ ) and $d$ takes values between 0 and 1: $d=0$ means no damage, whereas $d=1$ means that the complete damage grade is expected with a probability equal to 1 . The value of $d$ is also related to the mean damage grade, $\mu_{\mathrm{d}}$, as shown in the following equation: 


$$
d=\frac{\mu_{d}}{N-1} \text { and } \mu_{d}=\sum_{k=0}^{N-1} k P_{k}(N, d)
$$

$\mu_{\mathrm{d}}$ takes values between 0 and $N-1$, which correspond to values between 0 and 5 in this case. Equivalent beta probability functions are often used to quantify the probabilities of occurrence of the damage grades. The following semi-empirical functions are used to estimate $\mu_{\mathrm{d}}$ for any building defined by its vulnerability index (VI) and for any earthquake scenario defined by its macroseismic intensity $(I)$ :

$$
\mu_{\mathrm{d}}=2.5\left(1+\tanh \frac{I+6.25 V I-13.1}{2.3}\right)
$$

The macroseismic intensity I usually ranges from V (5) to XII (12), and $\mu_{\mathrm{d}}$ ranges from 0 (no damage) to 5 (destruction). Equation (4) was developed (Giovinazzi, 2005; Lagomarsino and Giovinazzi, 2006) in the framework of the Risk-UE project (Milutinovic and Trendafiloski, 2003) and is widely used to build risk scenarios in urban areas mainly because its compatibility with the EMS'98 macroseismic scale. Vulnerability indices lower than 0 and higher than 1 can be used in NVIM to represent extremely resistant buildings, including earthquake-resistant buildings, and extremely low quality buildings, respectively. In fact, the NVIM vulnerability indices (VI in this equation) and IVIM vulnerability indices ( $I_{\mathrm{v}}$ in Equation 1$)$ are not equivalent, mainly due to differences in the types of buildings to which they apply. Therefore, suitable assumptions are used to translate IVIM to NVIM vulnerability indices. Finally, the damage grade probabilities in Equation 2 are used to estimate other important risk-related outcomes such as number of casualties and economic cost.

\subsection{Damage scenarios}

Preliminary work showed that most of the constructions in this and other informal settlements in Mérida were highly vulnerable. Although NVIM provides preliminary guidelines for assessing vulnerability indices, IVIM is preferred for this study because it allows going through a detailed description of the seismic deficiencies of the buildings through twelve parameters, thus providing an accurate starting point for research. The guidelines provided by the IVIM method can be found in GNDT (2001), and a comprehensive description on the criteria to evaluate the parameters in Table 3 is given in Castillo (2006); the case of the new parameter 12 (adjacency) is discussed in subsection 3.1. It is worth noting that some of the criteria used in the evaluation of the buildings, as for instance parameter 3 (conventional resistance), are based on code-type structural analyses. The information required to score the twelve parameters in Table 3 was obtained from comprehensive in situ inspection. 19 distinct vulnerability indices, ranging between 0.38 and 0.85 , were obtained. For each vulnerability index, Figure 8 shows the 
corresponding percentage of buildings. Figure 9 shows the vulnerability distribution in the area. Table 4 shows the corresponding numerical values.

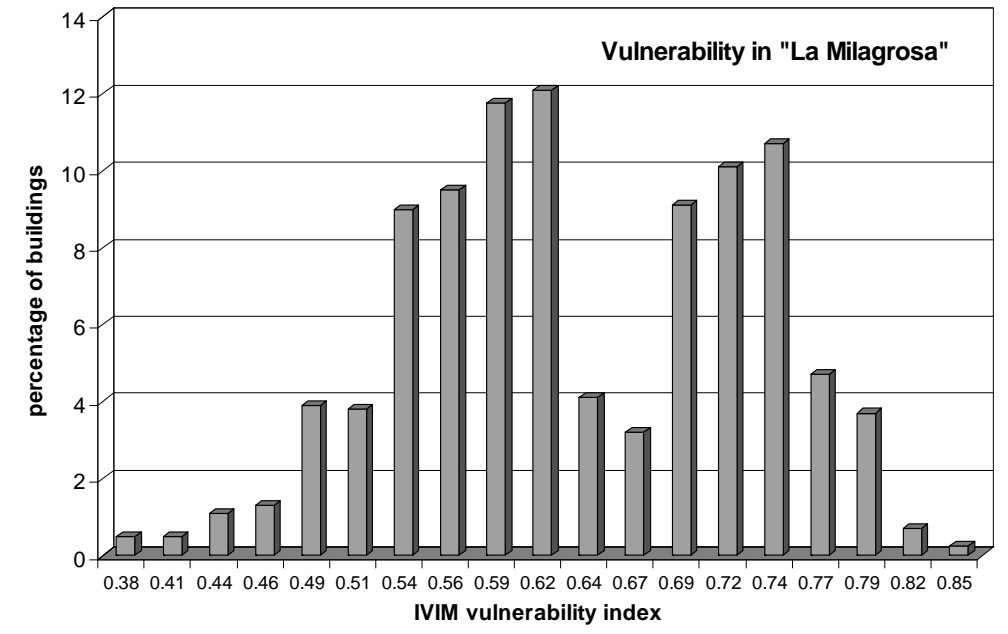

Fig. 8. Distribution of IVIM vulnerability indices.

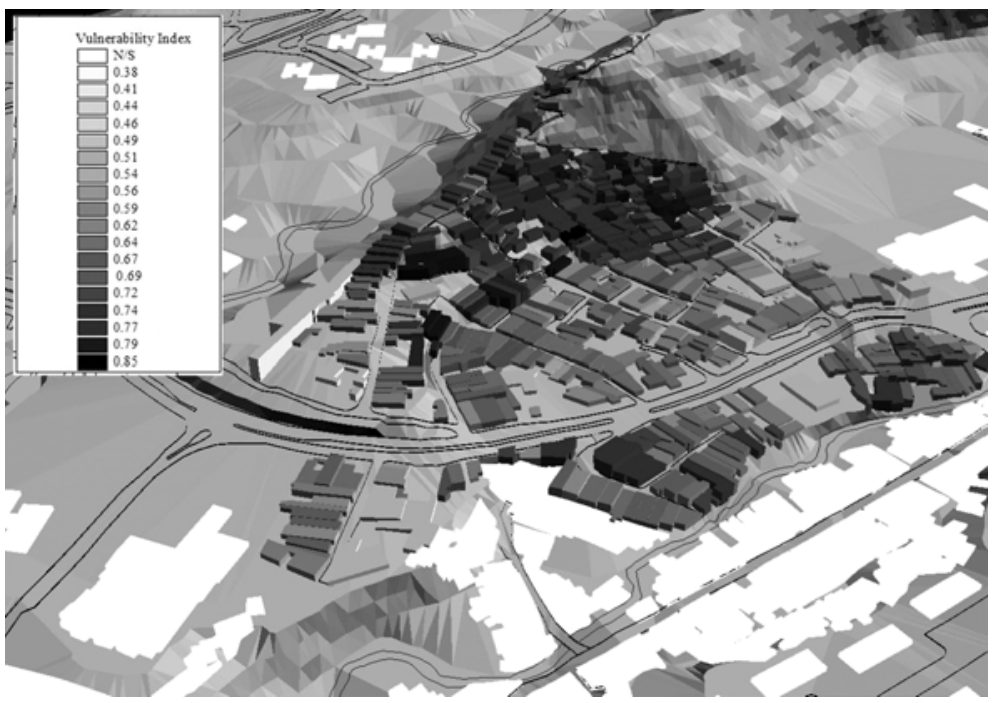

Fig. 9. Distribution of IVIM vulnerability indices in the settlement. N/S = not studied.

The following procedure was used to determine equivalent NVIM vulnerability indices. First, the predominant NVIM structural type in "La Milagrosa" (Table 2) was considered to be $R C$ moment resisting frame without seismic features ( $\mathrm{RC} 1$ type in (Milutinovic and Trendafiloski, 2003)). A building with the lowest IVIM vulnerability index was assumed to correspond to a pre-code building with regular plan and vertical configurations, a single story, and isolated footings. Due to the small building adjacency distances, this type of building was considered as aggregate. A building with the highest IVIM 
vulnerability index was assumed to correspond to a pre-code building founded over a pronounced slope and with irregular plan and vertical configurations, three floors, and isolated footings. The aggregate condition was maintained. Following NVIM guidelines, the corresponding NVIM vulnerability values for these buildings were estimated as 0.64 and 0.80 ; we were then able to determine that these values were equivalent NVIM vulnerability indices to IVIM indices of 0.48 and 0.85 , respectively. Finally, the corresponding NVIM vulnerability indices for intermediate values were assigned by linear interpolation. Table 4 summarizes the distribution of IVIM and NVIM vulnerability indices.

\begin{tabular}{ccc} 
Table 4. Distribution of IVIM and corresponding NVIM vulnerability indices \\
\hline $\begin{array}{c}\text { Percentage } \\
\text { of buildings }\end{array}$ & $\begin{array}{c}\text { IVIM } \\
\text { indices }\end{array}$ & NVIM \\
indices
\end{tabular}

The Boconó fault (Pérez, 1998) is the largest seismogenic source in western Venezuela and affects Mérida on its path through the central Venezuelan Andes. A probabilistic seismic hazard analysis showed that the annual probability of exceedance of seismic events with EMS'98 macroseismic intensities of VIII and IX are $1.17 \%$ and $0.12 \%$ respectively, being 86 and 831 years the corresponding return periods. We consider these two earthquake scenarios and analyze the expected damage, using the NVIM indices in Table 4 and Equations 2, 3 and 4. The expected mean damage grades are 2 (moderate) and 3 (severe) respectively for the VIII and IX intensity scenarios: in the first case, we estimate that approximately $30 \%$ of buildings would suffer damage of grade 3 (severe) or greater, whereas in the second case, more than $32 \%$ of buildings would suffer damage of grade 4 (extensive) or greater. Figure 10 shows the expected damage distributions. 


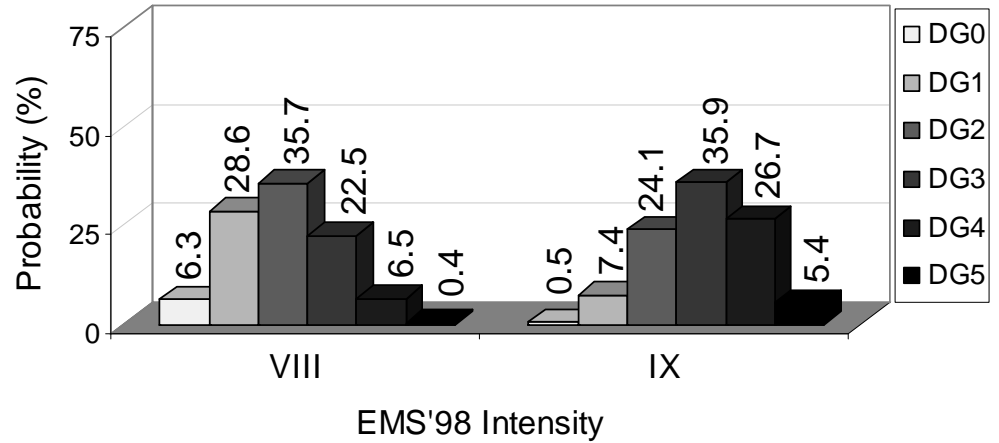

Fig. 10. Damage grade probabilities (\%) for intensity VIII and IX earthquake scenarios.

\section{Structural analysis and strengthening proposal}

\subsection{Behavior under gravity loads}

The strength of the prototype buildings under vertical loads is evaluated by using common structural analysis methods. A more detailed description can be found in (Castillo, 2006). The following paragraphs describe the performance of frames, walls and slabs, respectively.

Posts and ties. The structural analysis of the transversal frames (those supporting the joists, as shown in Figure 4, left) shows that they do not have the capacity to support the weight of the building, even under serviceability conditions. The bending and shear resistances of both posts and ties are clearly exceeded, even not accounting for the axial forces. The detailing is clearly inadequate; conversely, the risk of buckling (and, hence, of spalling) of the longitudinal bars is not considered serious. Consequently, the vertical loads are largely supported by the walls. These buildings must therefore be considered as intermediate RC frames - confined masonry walls according to the classification of nonengineered dwellings given in the Introduction section.

Walls. Even disregarding the contribution of the posts, the assumed compressive strength of the masonry (0.35 MPa; IAEE, 2001) is sufficient to withstand the gravity forces. Even for the tallest buildings (B3, see Figure 6), the average compressive stress $(0.195 \mathrm{MPa})$ does not exceed such strength. However, it would be dangerous to add another floor.

Slabs. The structural analysis of the steel joists (see Figure 4, left) shows that, disregarding the contribution of the top layer, the maximum normal stress largely exceeds the steel yield point (its nominal value is $250 \mathrm{MPa}$ ). Consequently, the contribution of the concrete layer must be considered. In such a case, the lacking of reliable shear connectors prevents to analyze each beam-topping assembly as a composite single member; by assuming that both layers share the bending moment according to their stiffness, it follows that the slabs are slightly unsafe according to regulatory standards. About the cantilevered part of the slabs (see Figure 6), the steel joists have the capacity to withstand the design loads, even neglecting the contribution of the topping concrete layer. 
From these verifications it follows that the demands exceed the resistances, mainly in the slabs. However, no structural pathologies have been observed or reported. This apparent inconsistency can be explained by the following considerations: (1) the actual situation corresponds to serviceability conditions while the strength has been verified for conservative ultimate limit states, (2) the actual live loads are significantly lower than those considered in the analysis, (3) the structural parameters of the materials have been conservatively estimated, and (4) the structural analysis has been carried out by assuming the most common conservative simplifications.

\subsection{Seismic analysis of the prototype buildings}

The horizontal seismic behavior of the prototype buildings is represented using lumpedmass models. Since the walls are significantly stiffer than the posts, they bear most of the horizontal forces, so the position of the center of rigidity is governed by the distribution of the walls (taking into account the openings). Figure 4 (left) shows that the buildings have a high degree of plan symmetry, because the eccentricities between the centers of mass and rigidity do not exceed $5 \%$ of the total building sizes (in both directions). Consequently, the behavior in each horizontal direction is represented using a 2-D model (with one degree of freedom per floor).

The equivalent force demands are determined according to the Venezuelan seismic design code (MINDUR and FUNVISIS, 1998). The fundamental periods $T$ of the buildings in both horizontal directions are obtained from the semi-empirical expressions given in that code: for prototype $\mathrm{B} 1, T=0.11 \mathrm{~s}$; for prototype $\mathrm{B} 2, T=0.19 \mathrm{~s}$; and for prototypes $\mathrm{B} 3, T=0.26 \mathrm{~s}$. The response reduction factor is taken as $R=1$ because of the lack of ductility due to the absence of seismic design criteria and the poor detailing. A more detailed description can be found in (Castillo, 2006). The resulting forces $F_{\mathrm{i}}$ are shown in Table 5; they are presented in terms of proportion of the gravity loads $W_{\mathrm{i}}$.

Table 5. Lateral force demands

\begin{tabular}{cccc}
\hline Prototype building & $F_{1} / W_{1}(\mathrm{kN})$ & $F_{2} / W_{2}(\mathrm{kN})$ & $F_{3} / W_{3}(\mathrm{kN})$ \\
\hline B1 & $309 / 383=0.81$ & - & - \\
B2 & $335 / 541=0.62$ & $227 / 183=1.24$ & - \\
B3-b and B3-c & $237 / 541=0.44$ & $475 / 541=0.88$ & $241 / 183=1.32$ \\
\hline
\end{tabular}

The walls are much stiffer horizontally than the RC frames; consequently, most of the lateral forces are carried by the walls before any damage is suffered. If the building is subjected to greater forces, several failure modes are possible (Paulay and Priestley, 1992):

- Shear failure of topped walls accompanied by failure of posts. This mode corresponds to failure of the masonry along horizontal mortar courses, generally at the mid-height of the panel. The resistance of the walls is determined by classical Mohr-Coulomb models (City University of London, 2005; Paulay and Priestley, 
1992; Magenes and Calvi, 1997); only the friction term can be accounted for because the contribution of the cohesion is not reliable for cyclic behavior. The effect of openings is compensated for by reducing the length of the wall by the equivalent distance. The resistance of the posts to shear failure is obtained according to the ACI criterion for seismic behavior (ACI 318, 2002); the contribution of the transversal steel is disregarded, since the excessive separation between consecutive stirrups allows shear cracks to form. Classical push-over analysis is used to determine the resistance of the posts to failure by plastic hinge formation; since sufficient rotation capacity is not provided (mainly due to the lack of transversal confinement), it is conservatively assumed that the posts fail after the first set of plastic hinges has formed.

- Diagonal strut compression failure of the topped walls accompanied by failure of confining elements. These walls must be in-plane with the posts and ties; otherwise there are no adjacent vertical supporting elements to provide diagonal compression. The strength of the walls is determined by classical strut-and-tie models (Paulay and Priestley, 1992).

- Collapse of unsupported elements. Due to the vertical component of the seismic action, some unsupported elements (i.e. vertically discontinuous walls and, in building B3-c, cantilevered walls) are at risk from vertical accelerations that could cause them to collapse. This is a serious risk, because the walls carry most of the weight and the supporting ties and slabs are already overloaded by the gravity demand.

- Out-of-plane failure of the untopped walls (those supporting light roofs). The resistance to this failure mode is difficult to estimate. Furthermore, it is unreliable given the poor quality of the mortar and the absence of upper collar beams and reliable ties (the roofs are light and weak).

- Detachment of the roof from supporting elements. The roofs are not connected rigidly to the supporting members (walls and posts) and are therefore at serious risk of falling (although the probability is difficult to estimate).

The first three failure modes are global, i.e. they could cause the building to collapse. To determine the resistance of the buildings, we obtain the most critical combination of these failure modes for each direction (i.e. the weakest loading path); the reference (Castillo, 2006) contains a deepest description of this operation. Table 6 shows the expected critical failure modes, strengths and demands for building B1. The demands exceed the strengths in both directions. The resistance in the longitudinal direction is considerably smaller than the transversal resistance, even though the walls are longer and have no openings; this effect is due to the premature shear failure of the posts, caused by the presence of the diagonal compression struts in the walls. The force demands on buildings B2 and B3 are higher than those on building B1 (Table 5), whereas the strengths and critical failure modes are largely the same. The cantilevers are at serious risk of collapse due to the vertical input. 
Table 6. Seismic behavior of building B1

\begin{tabular}{cccc}
\hline Direction & Failure mode & Strength $(\mathrm{kN})$ & Demand $(\mathrm{kN})$ \\
\hline$x$ (transversal) & Shearing of cladding and partitioning walls & 293 & 309 \\
$y$ (brittle) & Shearing of posts and partitioning walls \\
(brittle) & 174 & 309 \\
\hline
\end{tabular}

\subsection{Seismic strengthening proposal}

This subsection presents feasible strategies for reducing the seismic vulnerability of the non-engineered constructions in "La Milagrosa". It is assumed that all work will be carried out under expert technical supervision, even when performed by the owners of the buildings; therefore, rather than non-engineered construction, it should be termed "engineered self-construction". The main seismic deficiencies can be divided into three broad categories: poor resisting elements, pounding of adjoining buildings, and plan asymmetry (although the latter applies mainly to buildings not represented by the four prototypes). The proposed solutions are described next.

Walls. As mentioned above, the buildings are mainly supported by the cladding and partitioning walls. Consequently, these elements should not, under any circumstances, be partially or totally removed. New openings must be made carefully, using temporary props (vertically continuous down to the foundation) and installing lintels and jambs (made from reinforced concrete or steel). If there are partitioning walls which are not vertically continuous down to the foundation, new walls should be erected on the lower levels to guarantee the desired continuity. If possible, all walls which are not in-plane with the posts and ties should be moved to in-plane positions. In particular, upper-level cladding walls at the front of the building which are built over the edge of cantilevered slabs should be moved to a position that is in-plane with the frame, which would leave the slabs as balconies. No additional floors should be erected, even in the case of singlestory buildings.

Transversal walls. The transversal walls ( $x$ direction, both cladding and partitioning walls) should be coated with two layers of reinforced concrete (City University of London, 2005). This will harness the full strength capacity of the existing walls and provide additional lateral strength. The demands shown in Table 5 can be withstood easily. Particular attention should be paid to zones with stress concentrations that influence the collapse mechanism (e.g. corners or toes). The detailing should guarantee an even contact and proper anchorage with the surrounding supporting elements (e.g. slabs, ties and posts) to provide a smooth and sound load transfer. For first-floor walls, foundations are required to ensure a sufficient degree of confinement. Figure 11 shows a sample solution for a common situation. 


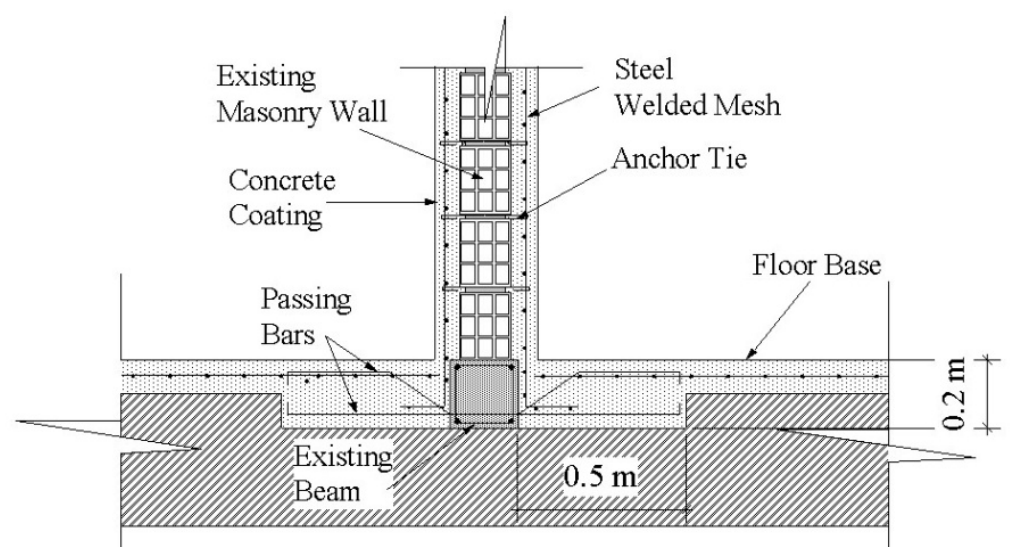

Fig. 11. Transversal wall jacketing.

Longitudinal walls. The longitudinal walls ( $y$ direction) can be strengthened in one of two ways: (1) by placing additional horizontal (hooked) steel reinforcement bars in the bed joints (by temporarily removing part of the mortar, inserting the bar, and re-grouting; see Figure 12, left) (Valluzzi, Binda and Modena, 2005); or (2) by lining one or both sides of the wall (Figure 12, right) with anchored layers of reinforced concrete (similar to Figure 11). These measures are intended to increase the resistance of the building to all possible failure modes: diagonal compression, horizontal shear and out-of-plane failure. Since these walls support a considerable proportion of the building's weight, this operation should be performed carefully, and props are required (they should be continuous down to the foundation). For first-floor walls, foundations are required and should be built in the same way as for the transversal walls (Figure 11).
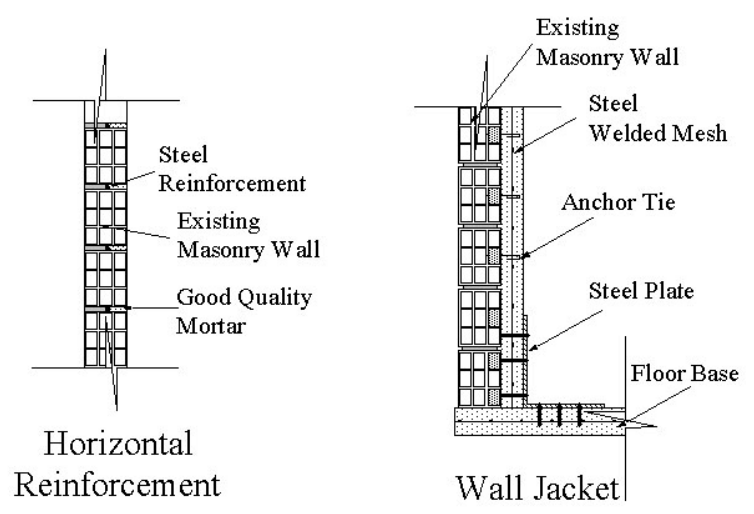

Fig. 12. Longitudinal wall strengthening.

Collar beams. Collar beams (ties) can be connected to the posts to top any untopped wall. These ties can have the same cross section and reinforcement as the frame members already in place. The beams are only intended to tie the upper portion of the wall and to 
support a light and non-detachable roof. Consequently, a floor must not be built over in any circumstances.

Pounding. If the slabs are unaligned (typically in steep sites), stiff and resistant elements (e.g. steel or timber bars) should be placed vertically between two buildings to reduce the most damaging effects of pounding. If the slabs are aligned, resistant but absorbing elements (e.g. timber pads) should be placed horizontally between any two adjoining slabs. These measures will reduce pounding and partially combine the seismic strengths of the two buildings.

Plan asymmetry. Asymmetric buildings can be re-symmetrized by adding infill walls in-plane with the frames or by closing some of the openings.

Roofs. Roofing should not be constructed from heavy materials (tiles, concrete blocks, massive steel members, etc.). Isolating zinc sheathing supported by light steel or timber elements is recommended. Heavy unanchored elements for preventing sheathing uplift (bricks, rock, tires, etc.) should not be used because they have a high risk of falling and add considerable weight.

Furniture and appliances. Heavy and tall furniture and appliances should be anchored to the floor or the posts; wall fixtures should be avoided because they could lead to out-of-plane failure.

Sewage. Excretal water should be drained to the public sewage system to prevent soil problems caused by local excess of water.

\section{Discussion and conclusions}

The "project value" (Coburn and Spence, 2002) is usually understood as the difference between the benefits of the project and the costs involved. In this section we discuss the effectiveness of the strengthening measures and carry out a socio-economic cost-benefit analysis. The IVIM method (see Table 3 and Equation 1) is used to evaluate the vulnerability of the four prototypes, before and after that all the proposed strengthening measures are properly implemented. Table 7 shows the results. Non-integer values for parameters 4, 6 and 8 correspond to intermediate classifications. Parameter 11 (state of preservation) is not considered, because we assume that it does not contribute to the vulnerability of the prototype buildings. Strengthening improves parameters 1, 2, 3 and 9 considerably, and the additional recommendations bring parameters 7, 8, 10 and 12 up to acceptable standards; such high improvements are mainly due to the extremely low values of the non-engineered buildings because of their poor quality and low ductility. Noticeably, although the strengthening of the walls will make them stiffer, this will not generate any increase in the spectral ordinates since in the natural periods of all the considered buildings lie clearly in the constant acceleration plateau region of the design spectrum (Castillo 2006). The IVIM vulnerability indices for unstrengthened buildings are consistent with those of the "La Milagrosa" building stock (see Table 2 and Figure 3), and are reduced by approximately $51 \%$ by the strengthening work. However, as pointed out above, NVIM indices are needed to determine the expected damage grades before and after strengthening; for unstrengthened prototypes, these are obtained by interpolation in 
Table 4. NVIM indices for strengthened prototypes are obtained by applying the same reduction factors as found for IVIM indices. Then, Equation (4) is used to estimate the expected mean damage grade. Table 7 shows the results for the selected earthquake scenarios. The expected damage is reduced dramatically; the average reduction factor of the mean damage grades is 3.7 for the intensity IX earthquake scenario. The damage analysis described in subsection 2.3 was repeated but with the assumption that all buildings had been strengthened; Figure 13 is the equivalent of Figure 10 for this new scenario.

Table 7. Vulnerability index assessment of the prototype buildings and expected damage for the two selected

\begin{tabular}{|c|c|c|c|c|c|c|c|c|c|}
\hline \multirow{2}{*}{ No. } & \multirow{2}{*}{ Parameter } & \multicolumn{4}{|c|}{ Un-strengthened buildings } & \multicolumn{4}{|c|}{ Strengthened buildings } \\
\hline & & B1 & B2 & B3-b & B3-c & B1 & $\mathrm{B} 2$ & B3-b & B3-c \\
\hline 1 & $\begin{array}{l}\text { Type and configuration of } \\
\text { resisting system }\end{array}$ & 8 & 8 & 8 & 8 & 4 & 4 & 4 & 4 \\
\hline 2 & Quality of resisting system & 2 & 2 & 2 & 2 & 1 & 1 & 1 & 1 \\
\hline 3 & Conventional resistance & 1 & 1 & 1 & 1 & -1 & 0 & 0 & 0 \\
\hline 4 & Location and soil condition & 0.5 & 0.5 & 0.5 & 0.5 & 0.5 & 0.5 & 0.5 & 0.5 \\
\hline 5 & Diaphragms & 1 & 1 & 1 & 2 & 1 & 1 & 1 & 1 \\
\hline 6 & Plan configuration & 0.5 & 0.5 & 0.5 & 1 & 0.5 & 0.5 & 0.5 & 0.5 \\
\hline 7 & Vertical configuration & 0 & 2 & 6 & 6 & 0 & 2 & 2 & 2 \\
\hline 8 & $\begin{array}{c}\text { Connectivity between } \\
\text { elements }\end{array}$ & 1 & 1 & 1 & 1 & 0.5 & 0.5 & 0.5 & 0.5 \\
\hline 9 & $\begin{array}{c}\text { Low-ductility structural } \\
\text { members }\end{array}$ & 2 & 2 & 2 & 2 & 1 & 1 & 1 & 1 \\
\hline 10 & Non-structural elements & 1 & 1 & 1 & 1 & 0 & 0 & 0 & 0 \\
\hline 11 & State of preservation & 0 & 0 & 0 & 0 & 0 & 0 & 0 & 0 \\
\hline \multirow[t]{5}{*}{12} & Adjacency & 0 & 1 & 4 & 4 & 0 & 0 & 2 & 2 \\
\hline & IVIM Vulnerability index & 0.462 & 0.538 & 0.718 & 0.756 & 0.218 & 0.295 & 0.346 & 0.346 \\
\hline & NVIM vulnerability Index & 0.668 & 0.694 & 0.755 & 0.768 & 0.315 & 0.380 & 0.364 & 0.351 \\
\hline & Mean damage grade $I=$ VIII & 1.70 & 1.87 & 2.29 & 2.38 & 0.33 & 0.46 & 0.42 & 0.40 \\
\hline & Mean damage grade $I=I X$ & 2.76 & 2.94 & 3.34 & 3.42 & 0.72 & 0.98 & 0.91 & 0.85 \\
\hline
\end{tabular}

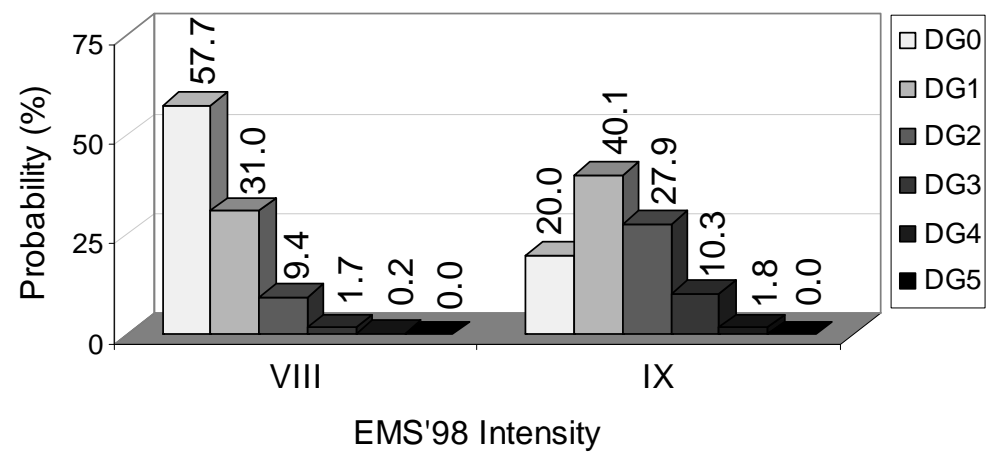

Fig. 13. Damage grade probabilities (\%) for strengthened buildings for intensity VIII and IX earthquake scenarios. 
For intensity VIII and IX earthquake scenarios, the expected mean damage grades are 1.96 and 2.97, respectively, for unstrengthened buildings, and 0.56 and 1.34 for strengthened buildings. These values are consistent with those found for the prototype buildings, although the prototypes show slightly lower damage values because parameter 11 was not been considered in the IVIM vulnerability index analysis. Consequently, the real buildings may have slightly higher vulnerability indices.

It is worth noting that Table 7 and Figures 10 and 13 correspond to two extreme cases: original non-engineered and successfully fully-strengthened buildings. To have an idea of the benefits of minor or partial strengthening measures, equation (4) has been used to assess the reduction of the expected mean damage grade that corresponds to the decrease in the vulnerability index. Four scenario cases, defined by the macroseismic intensities VI, VII, VIII and IX, are considered. The NVIM vulnerability index is considered to diminish from the maximum value, 0.768 , to the minimum value, 0.315 , in Table 7. Then, the corresponding expected mean damage grades and the relative reduction of the vulnerability index and of the mean damage grade are obtained. The computations are performed for the four scenario cases. Figure 14.a shows the mean damage grade as a function of the vulnerability index; Figure 14.b shows the reduction in the expected mean damage grade as a function of the decrease in the vulnerability index.

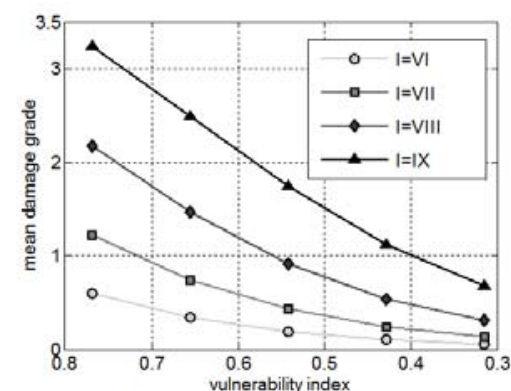

(a) $\mu_{\mathrm{d}}$ Vs. VI

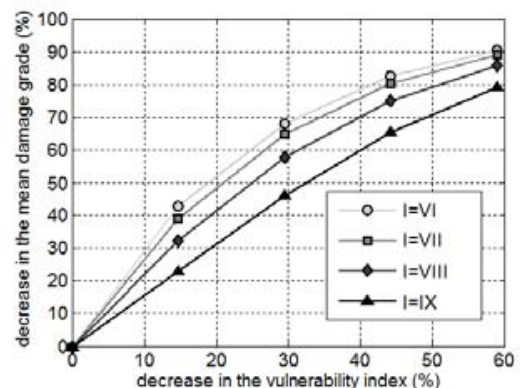

(b) Reduction of $\mu_{\mathrm{d}}$ vs. reduction of $V I$

Fig. 14. Influence in the expected damage of the decrease in the vulnerability index.

A reduction of about $30 \%$ in the vulnerability index leads to a decrease between about 50 and $70 \%$ in the expected mean damage grade; a reduction of $50 \%$ in the vulnerability index produces a decrease in the mean damage grade ranging in between 70 and $85 \%$. Thus, Figure 14 shows how even minor or partial strengthening measures lead to significant benefits in the expected damage.

The considerable reduction in the expected physical damage to buildings leads to other important benefits. To estimate the value of a large-scale building strengthening project, two essential losses in earthquake disasters are first evaluated: casualties and economic cost. Next, the monetary cost of the strengthening measures can be assessed to determine the estimated value of the project. The casualty model is defined using the following equation: 


$$
K_{\mathrm{s}}=C M_{1} M_{2} M_{3}\left[M_{4}+M_{5}\left(1-M_{4}\right)\right]
$$

$K_{\mathrm{S}}$ is the number of expected casualties; $C$ is the number of collapsed buildings, which is related to the probabilities of damage grades 4 (extensive) and 5 (collapse); $M_{1}$ is the number of people per building, which in this case is considered to be the average family size per house; $M_{2}$ is the occupancy rate of the buildings, which depends on the time of day; $M_{3}$ is the percentage of occupants trapped by the collapse; $M_{4}$ is related to the distribution of injury severity levels at collapse, since only a certain proportion of the occupants are killed whereas others are injured; and $M_{5}$ is only used to estimate fatalities and refers to mortality post-collapse. There are different ways of quantifying these parameters. (Vacareanu et al., 2004) provide detailed guidelines and numerical values for specific case studies; these figures and guidelines are based mainly on those given by (Coburn and Spence, 2002) and (Coburn and Spence, 1992). In this case study the casualty model was applied for VIII and IX earthquake scenarios.

Parameter $C$ is obtained from the probabilities of damage grades 4 (extensive) and 5 (collapse). Damage grade 4 includes partial collapse, and it is assumed here that partial collapse may produce casualties. We also assume that only the upper floors of half of the buildings suffering damage grade 4 (extensive) actually collapse. According to the Venezuelan census the average family has 4.3 members, so for each type of construction the total number of people per building is obtained by multiplying the average number of floors by 4.3. The resulting values of $M_{1}$ are between 4.3 and 12.9, and $M_{2}$ ranges from $80 \%$ at night to $30 \%$ at midday. In this study we consider the overnight scenario. Nonearthquake-resistant buildings are considered for $M_{3}$ values, which are $30 \%$ and $60 \%$ for macroseismic intensities VIII and IX respectively. $M_{4}$ for RC buildings and for atcollapse and post-collapse fatalities is $40 \% ; M_{5}$ for RC buildings takes values between $90 \%$ for communities capable of organizing rescue activities and $70 \%$ for communities served by emergency rescue teams. In this study we set the value to $80 \%$. Table 8 shows the results. Strengthening reduces the expected number of casualties considerably.

We now describe the procedure used to assess the economic cost. Only damage grades 4 (extensive) and 5 (complete) are considered. The probabilities of occurrence of these grades can be used to estimate the number of damaged buildings, including collapsed houses and dwellings suffering irreparable damage. As for casualty estimations, we consider that only the upper floors of half of the buildings suffering damage of grade (4) are irreparable. Current construction prices are used to estimate the reposition costs. A gross estimation of this value, including debris, contents and repair, is US $\$ 160 / \mathrm{m}^{2}$. In addition, if we take into account that the average area of each single-family flat is around $90 \mathrm{~m}^{2}$, the individual reposition cost is approximately US\$14,400. The calculations are used to estimate the economic impact of the earthquake scenarios considered in this study. Table 8 also shows the expected economic losses. The strengthening work has shown to be effective. 
Table 8 . Benefits of the strengthening

\begin{tabular}{|c|c|c|c|c|}
\hline \multirow[b]{2}{*}{$\begin{array}{c}\text { Input } \\
\text { intensity }\end{array}$} & \multicolumn{2}{|c|}{ Unstrengthened buildings } & \multicolumn{2}{|c|}{ Strengthened buildings } \\
\hline & $\begin{array}{c}\text { Economic losses (in } \\
\text { US\$ millions) }\end{array}$ & Fatalities & $\begin{array}{c}\text { Economic losses (in } \\
\text { US\$ millions) }\end{array}$ & Fatalities \\
\hline$I=\mathrm{VIII}$ & 1.34 & 45 & 0.04 & 2 \\
\hline$I=\mathrm{IX}$ & 5.36 & 275 & 0.39 & 10 \\
\hline
\end{tabular}

The cost of the strengthening project was estimated taking into account the current status of the construction sector in Venezuela. The total cost was determined by estimating the retrofit costs for the prototype buildings B1, B2 and B3 (taken as an average of B3-b and B3-c) and multiplying each cost by the number of buildings of each type with one, two and three floors, respectively. The cost of the following tasks was assessed: improvement of foundations, wall jacketing, improvements of beams and walls, suppression of cantilevers, and roof fixing. A detailed value analysis is given in (Castillo, 2006). The approximate cost of the proposed strengthening work for the whole settlement is estimated as US\$1,040,000.

According to the government of Venezuela, the construction cost of self-built dwellings is approximately US $\$ 220 / \mathrm{m}^{2}$. However, these dwellings are of higher quality than those in "La Milagrosa". Taking into account the built area in this part of the city, the total cost of providing new houses for all of the inhabitants would be US\$18,620,000. Labor costs are not included because the work is carried out by the owners; in addition, the government provides technical advice and supervision. The monetary cost of a life is a controversial value, because life is considered priceless. However, most insurance companies and an important number of national governments have their own figures; for example, a cost-effectiveness study carried out in Turkey by (Spence et al., 2002) gave a cost-per-life of between US\$250,000 and US\$750,000. Financial quantification of casualties is not performed here, although it should be noted that these issues, if included in the cost assessment, would increase the overall value of the strengthening project considerably.

The main conclusions of this work are:

- A detailed case study has shown that non-engineered buildings in informal settlements around the world, particularly in developing and seismic-prone countries, are highly vulnerable to earthquakes. Risk studies incorporating well-known methods can be used to identify and map detailed earthquake scenarios, which is the first step in devising strengthening strategies to improve the seismic resistance of dwellings in areas of this type.

- The four prototype buildings are representative of dwellings in the "La Milagrosa" settlement. Detailed structural analyses and code-type studies confirm that all of these buildings provide inadequate seismic performance. This information is then used to develop simple and inexpensive but effective strengthening measures.

- Moderate investment -less than $6 \%$ of the construction cost- can provide a reasonable level of seismic protection. 
- Strengthening measures can produce major benefits in case of earthquake: the expected degree of damage is reduced considerably and, consequently, the number of expected casualties and the economic cost fall dramatically.

- Taking into account the uses and the socio-economic context of these types of informal settlements, self-construction might be acceptable for seismic retrofitting, although expert technical supervision is essential.

- The methodology used in this paper can be applied, with minor modifications, to most informal settlements in South America. In addition, the results and conclusions can be extrapolated to an important number of informal settlements in cities located in other seismic-prone areas. Note that "La Milagrosa" was chosen because it is highly representative.

\section{Acknowledgements}

The thorough revision of the paper of two anonymous referees is greatly appreciated. The thoughtful comments and suggestions of the reviewers helped to improve the manuscript. This work was supported by the Spanish Government under projects CGL-2005-04541C03-03 and CGL2008-00869/BTE, which receive ERDF funding from the European Commission. A. Castillo received funding for the period of research spent in Barcelona from the Venezuelan National Council for Scientific and Technological Research (CONICIT), under grant \#199601500.

\section{References}

ACI Committee 318: 2002, Building Code Requirements for Structural Concrete (ACI 318-02) and Commentary, American Concrete Institute, Detroit, Michigan.

ATC-13: 1985, Earthquake damage evaluation data for California, Applied Technology Council, Redwood City.

ATC-40: 1996, Seismic evaluation and retrofit of concrete buildings, Technical report, Applied Technology Council, Redwood City, California.

Angeletti, P., Bellina, A., Guagenti, E., Moretti, A. and Petrini, V.: 1988, Comparison between vulnerability assessment and damage index, some results, Proceedings of the $9^{\text {th }}$ World Conference on Earthquake Engineering, Tokyo- Kyoto, Japan.

Barbat, A.H., Yépez, F. and Canas, J.A.: 1996, Damage scenarios simulation for seismic risk assessment in urban zones, Earthquake Spectra, 12(3), 371-394.

Barbat, A.H., Mena, U. and Yépez, F.: 1998, Evaluación probabilista del riesgo sísmico en zonas urbanas, Revista internacional de métodos numéricos para cálculo y diseño en ingeniería, 14(2), 247-268.

Barbat, A.H., Lagomarsino, S. and Pujades, L.G.: 2006a, Vulnerability assessment of dwelling buildings, C. Sousa, A. Roca, and X. Goula, eds. Assessing and managing earthquake risk. Dordrecht, The Netherlands.

Barbat, A.H., Pujades, L.G., Lantada, N. and Moreno, R.: 2006b, Performance of buildings under earthquake in Barcelona, Spain, Computer-Aided Civil Infrastructure Engineering, 21, 573593.

Barbat, A.H., Pujades, L.G., Lantada, N. and Moreno, R.: 2008, Seismic damage evaluation in urban areas using the capacity spectrum method: application to Barcelona, Soil Dynamics and Earthquake Engineering, 28(10-11), 851-865. 
Barbat, A.H., Carreño, M.L., Pujades, L.G., Lantada, N., Cardona, O.D. and Marulanda, M.C.: 2009, Seismic vulnerability and risk evaluation methods for urban areas. A review with application to a pilot area, Structural Infrastructure Engineering, 6(1), 17-38.

Bolívar, T., (Coordinator): 1994, Densificación y vivienda en los barrios Caraqueños. Contribución a la determinación de problemas y soluciones, Consejo Nacional de la Vivienda (CONAVI), Ministerio de Desarrollo Urbano, Caracas.

Carreño, M.L., Cardona, O.D. and Barbat, A.H.: 2007, Urban seismic risk evaluation: a holistic approach, Natural Hazards, 40, 137-172.

Castillo, A.: 2006, Seismic Risk Scenarios for Buildings in Mérida, Venezuela. Detailed Vulnerability Assessment for Non-Engineered Housing, Doctoral Dissertation, Technical University of Catalonia, Barcelona. Available online at: http://www.tdx.cat/TDX-0303106104140 (last accessed November $2^{\text {nd }}, 2010$ ).

City Univ. of London: 2005, Low-rise residential construction detailing to resist earthquakes, http://www.staff.city.ac.uk/earthquakes/Repairstrengthening/RSBrickMasonry.htm (last accessed November $\left.2^{\text {nd }}, 2010\right)$.

Coburn, A. and Spence, R.: 1992, Earthquake Protection, John Wiley.

Coburn, A. and Spence, R.: 2002, Earthquake Protection ( $2^{\text {nd }}$ edition). John Wiley.

Dolce, M., Kappos, A., Masi, A., Penelis, G. and Vona, M.: 2006, Vulnerability assessment and earthquake damage scenarios of the building stock of Potenza (Southern Italy) using Italian and Greek methodologies, Engineering Structures, 28, 357-371.

EERI/IAEE: 2005, Encyclopedia of Housing Construction Types in Seismically Prone Areas of the World, Earthquake Engineering Research Institute - International Association of Earthquake Engineering. At website: http://www.world-housing.net/index.asp.

ENV-1996: 1996, Design of masonry structures, European Committee for Standardization.

FEMA/NIBS: 2002, HAZUS technical manual -SR2, Federal Emergency Management Agency and National Institute of Building Sciences, Washington.

Giovinazzi, S. and Lagomarsino, S.: 2004, A macroseismic method for the vulnerability of buildings, Proceedings of the $13^{\text {th }}$ World Conference on Earthquake Engineering, Vancouver.

Giovinazzi, S.: 2005, The vulnerability assessment and the damage scenario in seismic risk analysis, PhD Dissertation, University of Florence. Italy. Electronic version online available at: http://bib1lp1.rz.tu-bs.de/docportal/content/below/index.xml.

GNDT: 2001, Scheda di Vulnerabilità Di $2^{\circ}$ Livello (Calcestruzzo Armato) and Scheda di Vulnerabilità Di $2^{\circ}$ Livello (Muratura), Downloaded at Gruppo Nazionale per la Difessa dai Terremoti:

www.ingv.it/gndt/Strumenti/Schede/Schede_vulnerabilita/scheda_secondo_livello_mur.pdf.

Grünthal, G.: 1998, European Macro-seismic Scale 1998, Centre Européen de Géodynamique et Séismologie, Cahiers du Centre Européen de Géodynamique et de Séismologie.

IAEE: 2001, Guidelines for Earthquake Resistant Non-Engineered Construction, International Association of Earthquake Engineering.

ISDR (International Secretariat for Disaster Reduction): 2001, Countering Disasters; Targeting Vulnerability, Information kit of the 2001 World Disaster Reduction Campaign, United Nations. At website: http://www.unisdr.org/unisdr/camp2001.htm.

Lagomarsino, S. and Giovinazzi, S.: 2006, Macroseismic and mechanical models for the vulnerability and damage assessment of current buildings, Bulletin of Earthquake Engineering, 4, 415-443.

Lantada, N., Pujades, L.G. and Barbat, A.H.: 2009, Vulnerability index and capacity spectrum based methods for urban seismic risk evaluation. A comparison, Natural Hazards, 51, 501524. 
Lantada, N., Irizarry, J., Barbat, A.H., Goula, X., Roca, A., Susagna, T. and Pujades, L.G.: 2010, Seismic hazard and risk scenarios for Barcelona, Spain, using the Risk-UE vulnerability index method, Bulletin of Earthquake Engineering, 8, 201-229.

Magenes, G. and Calvi, G.M.: 1997, In-plane seismic response of brick masonry walls, Earthquake

Engineering and Structural Dynamics, 26(11), 1091-1112.

Milutinovic, Z.V. and Trendafiloski, G.S.: 2003, Vulnerability of current buildings, Work-Package 4 of RISK_UE Project, European Commission, EVK4-CT-2000-00014.

MINDUR and FUNVISIS: 1998, Norma COVENIN 1756-98. Edificaciones Sismorresistentes, Dirección General Sectorial de Equipamiento del Ministerio de Desarrollo Urbano, Fundación Venezolana de Investigaciones Sísmicas, Caracas.

Murty, C.V.R., Brzev, S., Faison, H., Comartin, C.D. and Irfanoglu, A.: 2006, At Risk: The Seismic Performance of Reinforced Concrete Frame Buildings with Masonry Infill Walls, Earthquake Engineering Research Institute - International Association of Earthquake Engineering.

Musson, R.M.W., Grünthal, G. and Stucchi, M.: 2010, The comparison of macroseismic intensity scales, Journal of Seismology, 14(2), 413-428.

Paulay, T. and Priestley, M.N.J.: 1992, Seismic Design of Reinforced Concrete and Masonry Buildings, John Wiley.

Park, J., Towashiraporn, P., Craig, J.I. and Goodno, B.J.: 2009, Seismic fragility analysis of lowrise unreinforced masonry structures, Engineering Structures, 31, 125-137.

Pérez, O.: 1998, Seismological Report on the $M_{\mathrm{w}}=6.8$ Strong Shock of 9 July 1997 in Cariaco, Northeastern Venezuela, Bulletin of the Seismological Society of America, 31(3), 874-879.

Pujades, L.G., Barbat, A.H., González-Drigo, R., Ávila, J. and Lagomarsino, S.: 2010, Seismic performance of a block of buildings representative of the typical construction in the Eixample district in Barcelona (Spain), Bulletin of Earthquake Engineering, DOI 10.1007/s10518-0109207-5 (in press, published online September 15, 2010).

Sidetur: 2004, Losas de tabelones, Siderúrgica del Turbio S.A. www.sidetur.com.ve.

Vacareanu, R., Lungu, D., Aldea. A. and Arion, C.: 2004, Seismic Scenarios Handbook, RISK-UE LM1.

Valluzzi, M.R., Binda, L. and Modena, C.: 2005, Mechanical behavior of historic masonry structures strengthened by bed joints structural repointing, Construction and Building Materials, 19, 63-73.

Yépez, F.: 1996, Methodology for risk and vulnerability assessment of structures applying simulation techniques (in Spanish), Doctoral Dissertation, Technical University of Catalonia, Barcelona.

\section{List of symbols}

$A, B, C$ : levels of contribution to vulnerability of each of the parameters in the IVIM methodology

$\mathrm{B} 1, \mathrm{~B} 2, \mathrm{~B} 3-\mathrm{b}, \mathrm{B} 3-\mathrm{c}$ : prototype buildings representing the vast majority of constructions in "La Milagrosa”

$C$ : number of collapsed floors for a given input intensity (for estimating the number of casualties in Eq. 5)

d: damage grade (Eq. 3)

$F_{\mathrm{i}}$ : lateral force demand on the $i$-th floor

I: input intensity ranging from I (1) to XII (12)

Iv: vulnerability index in the IVIM methodology (Eq. 1)

$k$ : damage grade ranging from 0 (no damage) to 5 (destruction)

$K_{\mathrm{i}}$ : scoring coefficient of the $i$-th parameter in the IVIM methodology

$K_{\mathrm{ic}}$ : highest possible scoring coefficient of the i-th parameter in the IVIM methodology

$K_{\mathrm{s}}$ : number of casualties for a given input intensity (Eq. 5) 
$M_{1}, M_{2}, M_{3}, M_{4}, M_{5}$ : parameters representing the number of fatalities in an earthquake scenario (Eq. 5)

$R$ : response reduction factor in the code-type seismic analysis

$T$ : fundamental period of a building

VI: NVIM vulnerability index (ranging from 0 to 1 )

$W_{\mathrm{i}}$ : weighting factor of the $i$-th parameter in the IVIM methodology; weight of the $i$-th floor $\mu_{\mathrm{d}}$ : mean damage grade (Eq. 4) 